\title{
Metachronous Gastric Cancer Following Curative Endoscopic Resection of Early Gastric Cancer
}

\author{
Seiichiro Abe ${ }^{1}$, Ichiro Oda ${ }^{1}$, Takeyoshi Minagawa ${ }^{2}$, Masau Sekiguchi', Satoru Nonaka ${ }^{1}$, Haruhisa Suzuki', Shigetaka Yoshinaga ${ }^{1}$, \\ Amit Bhatt ${ }^{3}$ and Yutaka Saito ${ }^{1}$ \\ ${ }^{1}$ Endoscopy Division, National Cancer Center Hospital, Tokyo, ${ }^{2}$ Department of Gastroenterology, Tonan Hospital, Sapporo, Japan, \\ ${ }^{3}$ Department of Gastroenterology and Hepatology, Digestive Disease Institute, Cleveland, OH, USA
}

This review article summarizes knowledge about metachronous gastric cancer (MGC) occurring after curative endoscopic resection (ER) of early gastric cancer (EGC), treatment outcomes of patients who developed MGC, and efficacy of Helicobacter pylori eradication to prevent MGC. The incidence of MGC following curative ER increases over time and is higher than in patients undergoing gastrectomy. Increasing age and multifocal EGC are independent risk factors for developing MGC. An MGC following curative ER is usually a small $(<20 \mathrm{~mm})$ and differentiated intramucosal cancer. Most MGC lesions are found at an early stage on semiannual or annual surveillance endoscopy and are successfully treated by further ER, with excellent long-term outcomes. Eradication of $H$. pylori may reduce the risk of MGC following ER of EGC, but further prospective studies with long-term outcomes are required. Surveillance endoscopy following gastric ER should be continued indefinitely, due to the risk of MGC even after successful $H$. pylori eradication. Risk stratification and tailored endoscopic surveillance schedules need to be developed. Clin Endosc 2018;51:253-259

Key Words: Metachronous gastric cancer; Endoscopic resection; Endoscopic mucosal resection; Helicobacter pylori; Surveillance endoscopy

\section{INTRODUCTION}

Approximately one million new gastric cancer cases occurred in 2012, making it the fifth most common malignancy and the third leading cause of cancer death worldwide. ${ }^{1}$ Development of screening esophagogastroduodenoscopy (EGD) programs has led to the detection of gastric cancer at earlier stages, and approximately half of all gastric cancers in Japan are detected at a stage when they are confined to the mucosa or submucosa. $^{2}$

Increasing numbers of early gastric cancer (EGC) cases have been treated with endoscopic resection (ER), as curative

Received: June 29, 2017 Accepted: July 27, 2017

Correspondence: Seiichiro Abe

Endoscopy Division, National Cancer Center Hospital, 5-1-1 Tsukiji, Chuo, Tokyo 104-0045, Japan

Tel: +81-3-3542-2511, Fax: +81-3-3542-3815, E-mail: seabe@ncc.go.jp ORCID: https://orcid.org/0000-0002-2736-6921

(c) This is an Open Access article distributed under the terms of the Creative Commons Attribution Non-Commercial License (http://creativecommons.org/ licenses/by-nc/3.0) which permits unrestricted non-commercial use, distribution, and reproduction in any medium, provided the original work is properly cited. resection was defined based on large retrospective cohort in surgery cases and the development of endoscopic submucosal dissection (ESD) has allowed for high en bloc and curative resection rates of EGC, regardless of size and location. ${ }^{3-6} \mathrm{Sev}-$ eral retrospective studies have shown excellent long-term outcomes in EGC patients undergoing curative gastric ESD. ${ }^{7-16}$ In addition, ESD preserves stomach function and maintains quality of life in those patients who achieve curative ER. ${ }^{17}$

A drawback of ER for EGC is the risk of developing metachronous gastric cancer (MGC) in the remaining native stomach. As the popularity of this technique increases, it is vitally important to characterize risk factors and long-term outcomes for those patients who develop MGC. This review article summarizes the definition, incidence, clinical characteristics, and outcomes of MGC.

\section{DEFINITION OF MGC}

Gastric cancer detected on surveillance EGD following cu- 
rative ER may be a de novo lesion, a previously invisible preclinical lesion, or a missed lesion. Determining which of these possibilities is the case can be extremely difficult. General consensus, based on previous publications, is that gastric cancers detected within 1 year after ER should be regarded as a missed synchronous gastric cancer. ${ }^{18-21}$ Thus, MGC is generally defined as a gastric cancer located distant from the original EGC over 1 year following index ESD.

\section{INCIDENCE OF METACHRONOUS GASTRIC CANCER FOLLOWING ENDOSCOPIC RESECTION}

Studies have reported an incidence of MGC following ER for EGC ranging from $2.7 \%$ to $15.6 \%$ (Table 1$)^{20,22-30}$ In these studies, all MGCs were detected on surveillance EGD, and no study reported detection of EGC by barium contrast or computed tomography. ESD was preferred over endoscopic mucosal resection (EMR) in these series.

Kobayashi et al. reported that MGCs developed in 30 of 234 patients during a median follow-up of 5.0 years. ${ }^{28}$ They also demonstrated that a Kaplan-Meier curve of cumulative incidence of MGC stopped increasing after 10 years of follow-up. ${ }^{28}$ In contrast, Kato et al. and Min et al. reported that the cumulative incidence curve revealed a linear increase in much larger cohorts. ${ }^{24,29}$ We also demonstrated that 5-year, 7-year, and 10-year cumulative incidence of MGC (adjusted for risk of death from other causes) on surveillance endoscopy was $9.5 \%, 13.1 \%$, and $22.7 \%$, respectively, with a median follow up of 82.2 months. ${ }^{30}$
Following gastrectomy, the cumulative incidence of MGC is $0.9 \%-3.0 \%{ }^{31-34}$ The incidence of MGC in patients undergoing ER is much higher. This difference is explained by the organ-sparing nature of ER, as while maintaining luminal continuity offers an improved quality of life, the remaining gastric mucosa continues to be at risk of MGC.

\section{RISK FACTORS ASSOCIATED WITH MGC}

Although methods used to analyze risk factors for MGC vary among studies, older age, multiple initial EGCs and persistent Helicobacter pylori infection are considered to be common risk factors (Table 2). ${ }^{25,28-30,35-37}$ As older age is a greater potential risk factor for gastric cancer and multifocal lesions tend to develop in gastric mucosa with high risk field changes, these factors are unsurprising. Persistence of $H$. pylori infection as a risk factor is less straightforward. Persistence should be positively correlated with recurrence risk; however, Lim et al. reported that the absence of $H$. pylori infection is an independent risk factor for metachronous neoplasms, including dysplasia. ${ }^{38}$ One possible explanation for this divergent finding is that long-term $H$. pylori infection may result in severe atrophic gastritis with intestinal metaplasia, such that $H$. pylori is no longer detectable. Long-term infection might have had more effect on metachronous tumorigenesis than newly developed $H$. pylori infections that can be easily detected. $^{39}$

Table 1. Incidence of Metachronous Gastric Cancer following Endoscopic Resection

\begin{tabular}{|c|c|c|c|c|c|c|}
\hline \multirow{2}{*}{$\begin{array}{l}\text { Study } \\
\text { Kim et al. }(2007)^{22}\end{array}$} & \multirow{2}{*}{$\begin{array}{c}\begin{array}{c}\text { Methods of } \\
\text { endoscopic resection }\end{array} \\
E M R^{\mathrm{a})}\end{array}$} & \multirow{2}{*}{$\begin{array}{c}\begin{array}{c}\text { Rate of } \\
\text { MGC }\end{array} \\
2.70 \%\end{array}$} & \multicolumn{3}{|c|}{ Follow up period (yr) } & \multirow{2}{*}{$\begin{array}{c}\text { Annual incidence of } \\
\text { MGC } \\
-\end{array}$} \\
\hline & & & $11 / 379$ & 1.9 & Median & \\
\hline Lee et al. $(2011)^{23}$ & ESD & $3.30 \%{ }^{b)}$ & $15 / 458$ & 2.2 & Median & - \\
\hline Kato et al. $(2013)^{24}$ & ESD & $5.20 \%$ & $65 / 1258$ & 2.2 & Mean & $3.50 \%$ \\
\hline Hahn et al. $(2016)^{25}$ & ESD & $4.30 \%$ & $58 / 1347$ & 2.4 & Median & $2.48 \%$ \\
\hline Nakajima et al. $(2006)^{26}$ & EMR and ESD & $8.20 \%$ & $52 / 633$ & 4.4 & Mean & - \\
\hline Nasu et al. $(2005)^{27}$ & EMR & $14 \%$ & $20 / 143$ & 4.8 & Median & Approximately $4 \%$ \\
\hline Kobayashi et al. $(2010)^{28}$ & EMR and ESD & $12.80 \%$ & $30 / 234$ & 5 & Median & - \\
\hline Min et al. $(2015)^{29}$ & ESD & $3.60 \%$ & $47 / 1306$ & 5 & Median & - \\
\hline Abe et al. $(2015)^{30}$ & ESD & $15.60 \%$ & $238 / 1527$ & 6.6 & Median & - \\
\hline Arima et al. $(1999)^{20}$ & EMR & $7.90 \%$ & $6 / 76$ & 7 & -c) & - \\
\hline
\end{tabular}

MGC, metachronous gastric cancer; EMR, endoscopic mucosal resection; ESD, endoscopic submucosal dissection.

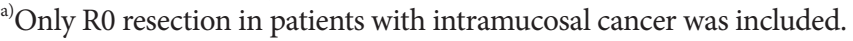

${ }^{\text {b) }}$ Synchronous lesion was included for analysis.

${ }^{c)}$ All patients were followed up for 7 year. 


\section{CLINICAL CHARACTERISTICS AND TREATMENT OUTCOMES OF MGC}

According to recent publications, MGCs are commonly characterized as small, differentiated intramucosal cancers $<20 \mathrm{~mm}$ in size. ${ }^{26-28}$ MGCs often develop when the initial lesion is a differentiated EGC. This suggests that this type of cancer tends to develop in gastric mucosa during field cancerization. ${ }^{40,41}$

Regular endoscopic surveillance detects MGC at an early stage, allowing for repeat curative ESD resection in the majority of cases, according to absolute or expanded indications based on the Japanese Gastric Cancer Treatment Guidelines. ${ }^{5,23-25,29,30}$ Kato et al. reported that only 4 of 175 synchronous or metachronous cancers invaded the submucosa or deeper layers. ${ }^{24}$ Our study showed that 215 of 238 patients with MGC underwent ER (mostly ESD), and the en bloc resection, R0 resection, and curative resection rates were 99.3\%, $94.3 \%$, and $88.8 \%$, respectively. ${ }^{30}$

In addition, excellent long-term outcomes have been shown by Kato et al. in his multicenter, retrospective cohort study, in which no patients died of gastric cancer during a mean follow-up period of 26.8 months. ${ }^{24}$ Our study showed a 5-year disease-specific survival rate of $99.2 \%$ in patients undergoing curative gastric ESD; of the 238 patients who developed MGC, only 7 died of MGC during a median follow-up of 82.2 months. The patients who died from MGC were lost to follow-up, and did not undergo the surveillance endoscopy that may have detected their cancers at an earlier and more treatable stage. Five of the patients died from MGC more than 5 years after their index ESD. ${ }^{30}$ These studies support the clin- ical validity of an organ-preserving strategy with surveillance endoscopy and repeated ESD.

Treatment outcomes for gastric cancer are generally evaluated with 5-year overall and disease-specific survival. A limited 5-year follow-up may be reasonable for patients undergoing gastrectomy, as a majority of postoperative lymph node or distant recurrences occur within 5 years, and the risk of MGC development is much lower than in those treated with $\mathrm{ER}^{42}$ On the other hand, indefinite endoscopic surveillance is required to detect and remove MGCs in patients treated endoscopically.

\section{H. PYLORI ERADICATION FOLLOWING ER}

H. pylori infection is characterized by progression through the following stages: chronic active gastritis, atrophy, intestinal metaplasia, and dysplasia, followed by the development of gastric adenocarcinoma. $\mathrm{H}$. pylori infection is considered one of the most important risk factors for gastric cancer. ${ }^{43-47}$ In 1994, the International Agency for Research on Cancer, a subsidiary of the World Health Organization, categorized $H$. pylori as a group 1 carcinogen for gastric cancer. ${ }^{48}$ Uemura et al. concluded that gastric cancer develops in persons infected with $H$. pylori, but not in uninfected persons. ${ }^{49}$ Take et al. showed that $H$. pylori eradication has preventative effects on the occurrence of initial gastric cancer..$^{50}$ In addition, persistent $H$. pylori infection was considered to a risk factor for MGC after ER in a number of retrospective studies, as shown in Table 2. ${ }^{36,37}$

Thus, it would seem reasonable to assume that $H$. pylori

Table 2. Intervals of Surveillance Endoscopy and Risk Factors of Metachronous Gastric Cancer following Endoscopic Resection

\begin{tabular}{lll}
\hline Study & $\begin{array}{l}\text { Intervals of Surveillance } \\
\text { endoscopy for MGC }\end{array}$ & \multicolumn{1}{c}{ Risk factors of metachronous gastric cancers } \\
\hline Lee et al. $(2011)^{23}$ & Biannual then annual & - \\
Kato et al. $(2013)^{24}$ & Annual or biannual & - \\
\hline Hahn et al. $(2016)^{25}$ & Annual or biannual & Older age, intestinal metaplasia, ESD criteria \\
\hline Nakajima et al. $(2006)^{26}$ & Annual & - \\
\hline Nasu et al. $(2005)^{27}$ & Annual & - \\
\hline Kobayashi et al. $(2010)^{28}$ & Annual & Multiple initial EGC, male, same third of the stomach \\
\hline Min et al. $(2015)^{29}$ & Annual or biannual & Multiple initial EGC, well differentiated adenocarcinoma of initial EGC \\
\hline Abe et al. $(2015)^{30}$ & Annual or biannual & Multiple initial EGC, male \\
\hline Arima et al. $(1999)^{20}$ & - & Multiple initial EGC \\
Maehata et al. $(2012)^{35}$ & Annual or biannual & Follow-up period over 5 years, severe gastric mucosal atrophy \\
Kwon et al. $(2014)^{36}$ & Annual & Age $\geq 60$ years old, persistent Helicobacter pylori infection \\
\hline Kim et al. $(2014)^{37}$ & Annual & Age $\geq 65$ years old, persistent H.pylori infection, family history of gastric cancer \\
\hline
\end{tabular}

MGC, metachronous gastric cancer; ESD, endoscopic submucosal dissection; EGC, early gastric cancer. 
eradication would have a potential prophylactic effect on MGC following ER. ${ }^{51}$ However, two recent large, prospective randomized trials have shown contradictory results. Fukase et al. reported that the cumulative incidence of MGC was 6.5\% during a 3-year follow-up, and patients receiving $H$. pylori eradication treatment showed significantly lower MGC rates than patients without eradication therapy (3.5\% vs. 9.6\%, $p=0.003) .{ }^{52}$ On the other hand, Choi et al. concluded that the cumulative incidence of MGC was comparable in patients with and without $H$. pylori eradication treatment during a 3-year follow-up (2.3\% vs. $3.9 \%, p=0.24) .{ }^{53}$ Other retrospective studies showed similarly controversial conclusions (Table 3), ${ }^{35-37,54-58}$ but meta-analyses by Jung et al. and Yoon et al. concluded that $H$. pylori eradication could play a preventative role by reducing the occurrence of MGC in patients who have undergone ER..$^{59,60}$

Therefore, $H$. pylori eradication should be considered as preventative of MGC after ER. It should be noted that the definitions of MGC were not consistent among the studies and that some previous studies did not distinguish MGC from synchronous gastric cancer. In addition, the median follow-up periods were less than 5 years in a majority of previous publications and the timing of $H$. pylori eradication could affect the results. Further prospective studies in the ESD era with long follow-up periods might help clarify the preventative effect of $H$. pylori eradication for MGC occurrence.

\section{CLINICAL CHARACTERISTICS AND RISK FACTORS OF MGC FOLLOWING H. PYLORI ERADICATION}

MGCs following successful $H$. pylori eradication were mainly characterized as small, differentiated EGCs. Mori et al. showed that MGCs were $15 \mathrm{~mm}$ in median tumor size, and were commonly located at the middle or lower third of the stomach. ${ }^{61}$ Of these, $97 \%$ of MGCs were differentiated EGCs and $90 \%$ of these were confined to the mucosa. $\mathrm{Cu}-$ rative ESD resection was done for all MGCs according to the Japanese Gastric Cancer Treatment Guidelines, except for one differentiated $\mathrm{T} 1 \mathrm{~b}$ (submucosal invasion to $80 \mu \mathrm{m}$ ) cancer $4 \mathrm{~mm}$ in size with lymphatic involvement. ${ }^{61}$ Regular endoscopic surveillance would probably play a significant role in early detection. MGCs following $H$. pylori eradication were sometimes covered by non-neoplastic epithelium.

This histological alteration made it more difficult to detect MGC and delineate its margin, even with magnified narrow-band imaging. ${ }^{62,63}$ Yamamoto et al. reported that the average diameter of an MGC following successful eradication was smaller and the Ki-67 index was lower than in cases with persistent $H$. pylori infection. ${ }^{64}$

Moribata et al. analyzed endoscopic mucosal background features associated with MGC in patients who underwent H. pylori eradication therapy and concluded the absence of intestinal metaplasia prior to ESD was a negative predictor of MGC after ESD, and the emergence of map-like redness

Table 3. Incidence of Metachronous Gastric Cancer following Successful Helicobacter pylori Eradication

\begin{tabular}{|c|c|c|c|c|c|c|c|}
\hline Study & Design & Number ${ }^{\text {a) }}$ & $\begin{array}{l}\text { Follo } \\
\text { Perio }\end{array}$ & $\begin{array}{l}\text { w up } \\
d(y r)\end{array}$ & Incidence & Effect & Results \\
\hline Uemura et al. $(1997)^{51}$ & NR & $65 / 67$ & - & - & $0.0 / 9.0 \%$ & Effective & $p=0.011$ \\
\hline Fukase et al. $(2008)^{52}$ & RCT & $255 / 250$ & $2.9 / 2.9^{a)}$ & Median & $3.5 / 9.6 \%$ & Effective & $p=0.003^{\mathrm{b})}, \mathrm{OR}=0.34$ \\
\hline Shiotani et al. $(2008)^{54}$ & Single arm & $-/ 80$ & 2.8 & Median & $11.3 \%$ & & \\
\hline Maehata et al. $(2012)^{35}$ & Retrospective & $177 / 91$ & 3 & Median & $8.5 / 14.3 \%$ & Non-effective & $p=0.262$ \\
\hline Choi et al. $(2014)^{53}$ & RCT & $439 / 441$ & 3 & Median & $2.3 / 3.9 \%$ & Non-effective & $p=0.15$ \\
\hline Seo et al. $(2013)^{55}$ & Retrospective & $61 / 13$ & 2.3 & Mean & $9.8 / 23.1 \%$ & Non-effective & $p=0.189, \mathrm{OR}=0.36$ \\
\hline Chon et al. $(2013)^{56}$ & Retrospective & $85 / 44$ & 2.2 & Median & $4.7 / 11.4 \%$ & Effective & $p=0.008, \mathrm{HR}=0.143$ \\
\hline Kwon et al. $(2014)^{36}$ & Retrospective & $214 / 69$ & 3.4 & Median & $4.7 / 14.5 \%$ & Effective & $p=0.009$ \\
\hline Kim et al. $(2014)^{37}$ & Retrospective & $49 / 107$ & $5.3 / 4.6^{\mathrm{a})}$ & Median & $4.1 / 15.0 \%$ & Effective & $p=0.006$ \\
\hline \multirow[t]{2}{*}{ Bae et al. $(2014)^{57}$} & Retrospective & $485 / 182$ & $5^{c)}$ & Median & $7.0 / 13.2 \%$ & Effective & $p=0.02, \mathrm{HR}=1.9$ \\
\hline & & & & & $14.7 / 29.7 / 1,000 \mathrm{pt} y r$ & & \\
\hline Jung et al. $(2015)^{58}$ & Retrospective & $506 / 169$ & $3.3^{\mathrm{c})}$ & Median & $4.2 / 5.9 \%$ & Non-effective & $p=0.29, \mathrm{HR}=0.67$ \\
\hline Mori et al. $(2016)^{61}$ & Single arm & $-/ 594$ & 4.5 & Median & $29.9 / 1,000 \mathrm{pt} y r$ & & \\
\hline
\end{tabular}

NR, non-randomized; RCT, randomized controlled trial; OR, odds ratio; HR, hazard ratio.

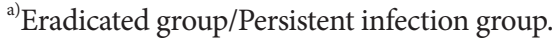

${ }^{b)}$ Modified intention to treat analysis.

${ }^{c}$ Including gastric dysplasia, including Helicobacter pylori non-infection group. 
after $H$. pylori eradication was a positive predictor for MGC after ESD. ${ }^{65}$ Mori et al. and Shiotani et al. supported this conclusion and showed that widespread gastric mucosal atrophy and multiple gastric cancers before successful $H$. pylori eradication were risk factors for MGC occurrence following $H$. pylori eradication. ${ }^{54,61}$

\section{SURVEILLANCE INTERVAL AND PERIOD}

There are some established guidelines for surveillance interval in patients undergoing curative ER. The National Comprehensive Cancer Network guidelines state that even for Tis or T1 with N0 lesions achieving R0 with ER or surgery, all patients should be followed up systematically, and follow-up should include a complete history and physical examination every 3 to 6 months for 1 to 2 years, every 6 to 12 months for 3 to 5 years, and annually thereafter all patients. ${ }^{66}$ The Japanese gastric cancer treatment guidelines recommend annual or biannual endoscopy after curative ESD for patients with EGC who meet expanded indications criteria. ${ }^{5}$

Given that most of the MGCs were found in early stages and were successfully treated with ER in many previous reports, annual or biannual endoscopic surveillance may be reasonable. As the individual risk of MGC can vary greatly among patients, risk stratification and tailored follow-up schedules should be considered, similar to surveillance colonoscopy after endoscopic polyp removal. ${ }^{67}$ In addition, we are performing a prospective study to evaluate epigenetic cancer risk prediction of MGC after $\mathrm{H}$. pylori eradication. We hope that these results will provide more detailed data on the stratification of risk factors for MGC following $H$. pylori eradication. ${ }^{68}$ Further prospective studies are warranted to determine appropriate surveillance intervals. Regarding the surveillance period, as the cumulative incidence of MGC linearly increased and some patients died of MGC more than 5 years after treatment, endoscopic surveillance should be performed indefinitely. ${ }^{30}$ In addition, Mori et al. reported that the 5-year cumulative incidence of MGC even after successful $H$. pylori eradication was $15.0 \%$ during a 4.5-year median follow-up period. ${ }^{61}$ This multicenter, prospective study also showed that $11 \%$ of MGCs (10 of 94) were detected more than 5 years after successful $H$. pylori eradication. ${ }^{61}$ Therefore, continuous surveillance endoscopy should be performed to identify MGC in patients who have undergone ER for EGC, regardless of success or failure of $H$. pylori eradication.

\section{CONCLUSIONS}

EGC patients who undergo ER are at significant risk of developing MGC, but with annual or biannual surveillance EGD, MGC can be detected at an early stage when it is amenable to curative ESD resection. $H$. pylori eradication may reduce the incidence of MGC, but does not completely eradicate risk. Surveillance endoscopy should be continued indefinitely as cumulative incidence of MGC linearly increases. As we gain understanding of MGC, we hope that tailored surveillance intervals are developed, similar to those used to predict colonoscopy surveillance intervals based on the characteristics of the polyps removed. ESD for EGC preserves the quality of life by retaining the native stomach; however, the native stomach is at high risk for developing other gastric cancers. These patients should undergo life-long endoscopic surveillance for detection of MCG at an early and treatable stage.

Conflicts of Interest

The authors have no financial conflicts of interest.

\section{Acknowledgements}

Part of this work was supported by the National Cancer Center Research and Development Fund (25-A-12 and 28-K-1).

\section{REFERENCES}

1. Ferlay J, Soerjomataram I, Dikshit R, et al. Cancer incidence and mortality worldwide: sources, methods and major patterns in GLOBOCAN 2012. Int J Cancer 2015;136:E359-E386.

2. Nashimoto A, Akazawa K, Isobe Y, et al. Gastric cancer treated in 2002 in Japan: 2009 annual report of the JGCA nationwide registry. Gastric Cancer 2013;16:1-27.

3. Gotoda T, Yanagisawa A, Sasako M, et al. Incidence of lymph node metastasis from early gastric cancer: estimation with a large number of cases at two large centers. Gastric Cancer 2000;3:219-225.

4. Hirasawa T, Gotoda T, Miyata S, et al. Incidence of lymph node metastasis and the feasibility of endoscopic resection for undifferentiated-type early gastric cancer. Gastric Cancer 2009;12:148-152.

5. Japanese Gastric Cancer Association. Japanese gastric cancer treatment guidelines 2010 (ver. 3). Gastric Cancer 2011;14:113-123.

6. Ono H, Yao K, Fujishiro M, et al. Guidelines for endoscopic submucosal dissection and endoscopic mucosal resection for early gastric cancer. Dig Endosc 2016;28:3-15.

7. Oda I, Saito D, Tada M, et al. A multicenter retrospective study of endoscopic resection for early gastric cancer. Gastric Cancer 2006;9:262-270.

8. Isomoto H, Shikuwa S, Yamaguchi N, et al. Endoscopic submucosal dissection for early gastric cancer: a large-scale feasibility study. Gut 2009;58:331-336.

9. Goto O, Fujishiro M, Kodashima S, Ono S, Omata M. Outcomes of endoscopic submucosal dissection for early gastric cancer with special reference to validation for curability criteria. Endoscopy 2009;41:118122.

10. Gotoda T, Iwasaki M, Kusano C, Seewald S, Oda I. Endoscopic resection of early gastric cancer treated by guideline and expanded National Cancer Centre criteria. Br J Surg 2010;97:868-871. 
11. Abe S, Oda I, Suzuki H, et al. Short- and long-term outcomes of endoscopic submucosal dissection for undifferentiated early gastric cancer. Endoscopy 2013;45:703-707.

12. Kosaka T, Endo M, Toya Y, et al. Long-term outcomes of endoscopic submucosal dissection for early gastric cancer: a single-center retrospective study. Dig Endosc 2014;26:183-191.

13. Tanabe S, Ishido K, Higuchi K, et al. Long-term outcomes of endoscopic submucosal dissection for early gastric cancer: a retrospective comparison with conventional endoscopic resection in a single center. Gastric Cancer 2014;17:130-136.

14. Oda I, Oyama T, Abe S, et al. Preliminary results of multicenter questionnaire study on long-term outcomes of curative endoscopic submucosal dissection for early gastric cancer. Dig Endosc 2014;26:214-219.

15. Ohnita $\mathrm{K}$, Isomoto $\mathrm{H}$, Shikuwa $\mathrm{S}$, et al. Early and long-term outcomes of endoscopic submucosal dissection for early gastric cancer in a large patient series. Exp Ther Med 2014;7:594-598.

16. Suzuki H, Oda I, Abe S, et al. High rate of 5-year survival among patients with early gastric cancer undergoing curative endoscopic submucosal dissection. Gastric Cancer 2016;19:198-205.

17. Choi JH, Kim ES, Lee YJ, et al. Comparison of quality of life and worry of cancer recurrence between endoscopic and surgical treatment for early gastric cancer. Gastrointest Endosc 2015;82:299-307.

18. Moertel CG, Bargen JA, Soule EH. Multiple gastric cancers; review of the literature and study of 42 cases. Gastroenterology 1957;32:1095-1103.

19. Uemura N, Okamoto S. Effect of Helicobacter pylori eradication on subsequent development of cancer after endoscopic resection of early gastric cancer in Japan. Gastroenterol Clin North Am 2000;29:819-827.

20. Arima N, Adachi K, Katsube T, et al. Predictive factors for metachronous recurrence of early gastric cancer after endoscopic treatment. J Clin Gastroenterol 1999;29:44-47.

21. Nishida T, Tsujii M, Kato M, et al. Endoscopic surveillance strategy after endoscopic resection for early gastric cancer. World J Gastrointest Pathophysiol 2014;5:100-106.

22. Kim JJ, Lee JH, Jung HY, et al. EMR for early gastric cancer in Korea: a multicenter retrospective study. Gastrointest Endosc 2007;66:693-700.

23. Lee $\mathrm{H}$, Yun WK, Min BH, et al. A feasibility study on the expanded indication for endoscopic submucosal dissection of early gastric cancer. Surg Endosc 2011;25:1985-1993.

24. Kato M, Nishida T, Yamamoto K, et al. Scheduled endoscopic surveillance controls secondary cancer after curative endoscopic resection for early gastric cancer: a multicentre retrospective cohort study by Osaka University ESD study group. Gut 2013;62:1425-1432.

25. Hahn KY, Park JC, Kim EH, et al. Incidence and impact of scheduled endoscopic surveillance on recurrence after curative endoscopic resection for early gastric cancer. Gastrointest Endosc 2016;84:628-638.e1.

26. Nakajima T, Oda I, Gotoda T, et al. Metachronous gastric cancers after endoscopic resection: how effective is annual endoscopic surveillance? Gastric Cancer 2006;9:93-98.

27. Nasu J, Doi T, Endo H, Nishina T, Hirasaki S, Hyodo I. Characteristics of metachronous multiple early gastric cancers after endoscopic mucosal resection. Endoscopy 2005;37:990-993.

28. Kobayashi M, Narisawa R, Sato Y, Takeuchi M, Aoyagi Y. Self-limiting risk of metachronous gastric cancers after endoscopic resection. Dig Endosc 2010;22:169-173.

29. Min BH, Kim ER, Kim KM, et al. Surveillance strategy based on the incidence and patterns of recurrence after curative endoscopic submucosal dissection for early gastric cancer. Endoscopy 2015;47:784-793.

30. Abe S, Oda I, Suzuki H, et al. Long-term surveillance and treatment outcomes of metachronous gastric cancer occurring after curative endoscopic submucosal dissection. Endoscopy 2015;47:1113-1118.

31. Onodera H, Tokunaga A, Yoshiyuki T, et al. Surgical outcome of 483 patients with early gastric cancer: prognosis, postoperative morbidity and mortality, and gastric remnant cancer. Hepatogastroenterology 2004;51:82-85.

32. Hosokawa O, Kaizaki Y, Watanabe K, et al. Endoscopic surveillance for gastric remnant cancer after early cancer surgery. Endoscopy 2002;34:469-473.

33. Ikeda Y, Saku M, Kishihara F, Maehara Y. Effective follow-up for recurrence or a second primary cancer in patients with early gastric cancer. Br J Surg 2005;92:235-239.

34. Nozaki I, Hato S, Kobatake T, et al. Incidence of metachronous gastric cancer in the remnant stomach after synchronous multiple cancer surgery. Gastric Cancer 2014;17:61-66.

35. Maehata Y, Nakamura S, Fujisawa K, et al. Long-term effect of Helicobacter pylori eradication on the development of metachronous gastric cancer after endoscopic resection of early gastric cancer. Gastrointest Endosc 2012;75:39-46.

36. Kwon YH, Heo J, Lee HS, Cho CM, Jeon SW. Failure of Helicobacter pylori eradication and age are independent risk factors for recurrent neoplasia after endoscopic resection of early gastric cancer in 283 patients. Aliment Pharmacol Ther 2014;39:609-618.

37. Kim YI, Choi IJ, Kook MC, et al. The association between Helicobacter pylori status and incidence of metachronous gastric cancer after endoscopic resection of early gastric cancer. Helicobacter 2014;19:194-201.

38. Lim JH, Kim SG, Choi J, Im JP, Kim JS, Jung HC. Risk factors for synchronous or metachronous tumor development after endoscopic resection of gastric neoplasms. Gastric Cancer 2015;18:817-823.

39. Venerito M, Malfertheiner P. Preneoplastic conditions in the stomach: always a point of no return? Dig Dis 2015;33:5-10.

40. Zaky AH, Watari J, Tanabe H, et al. Clinicopathologic implications of genetic instability in intestinal-type gastric cancer and intestinal metaplasia as a precancerous lesion: proof of field cancerization in the stomach. Am J Clin Pathol 2008;129:613-621.

41. McDonald SA, Greaves LC, Gutierrez-Gonzalez L, et al. Mechanisms of field cancerization in the human stomach: the expansion and spread of mutated gastric stem cells. Gastroenterology 2008;134:500-510.

42. Feng XY, Chen YB, Wang W, et al. Time-varying pattern of recurrence risk for gastric cancer patients. Med Oncol 2013;30:514.

43. Fuccio L, Zagari RM, Eusebi LH, et al. Meta-analysis: can Helicobacter pylori eradication treatment reduce the risk for gastric cancer? Ann Intern Med 2009;151:121-128.

44. Sipponen P, Hyvärinen H. Role of Helicobacter pylori in the pathogenesis of gastritis, peptic ulcer and gastric cancer. Scand J Gastroenterol Suppl 1993;196:3-6.

45. Huang JQ, Sridhar S, Chen Y, Hunt RH. Meta-analysis of the relationship between Helicobacter pylori seropositivity and gastric cancer. Gastroenterology 1998;114:1169-1179.

46. Eslick GD, Lim LL, Byles JE, Xia HH, Talley NJ. Association of Helicobacter pylori infection with gastric carcinoma: a meta-analysis. Am J Gastroenterol 1999;94:2373-2379.

47. Sipponen P, Kimura K. Intestinal metaplasia, atrophic gastritis and stomach cancer: trends over time. Eur J Gastroenterol Hepatol 1994;6 Suppl 1:S79-S83.

48. Schistosomes, liver flukes and Helicobacter pylori. IARC Working Group on the Evaluation of Carcinogenic Risks to Humans. Lyon, 7-14 June 1994. IARC Monogr Eval Carcinog Risks Hum 1994;61:1-241.

49. Uemura N, Okamoto S, Yamamoto S, et al. Helicobacter pylori infection and the development of gastric cancer. N Engl J Med 2001;345:784-789.

50. Take S, Mizuno M, Ishiki K, et al. The effect of eradicating helicobacter pylori on the development of gastric cancer in patients with peptic ulcer disease. Am J Gastroenterol 2005;100:1037-1042.

51. Uemura N, Mukai T, Okamoto S, et al. Effect of Helicobacter pylori eradication on subsequent development of cancer after endoscopic resection of early gastric cancer. Cancer Epidemiol Biomarkers Prev 1997;6:639-642.

52. Fukase K, Kato M, Kikuchi S, et al. Effect of eradication of Helicobacter pylori on incidence of metachronous gastric carcinoma after endoscopic resection of early gastric cancer: an open-label, randomised controlled trial. Lancet 2008;372:392-397.

53. Choi J, Kim SG, Yoon H, et al. Eradication of Helicobacter pylori af- 
ter endoscopic resection of gastric tumors does not reduce incidence of metachronous gastric carcinoma. Clin Gastroenterol Hepatol 2014;12:793-800.el.

54. Shiotani A, Uedo N, Iishi $\mathrm{H}$, et al. Predictive factors for metachronous gastric cancer in high-risk patients after successful Helicobacter pylori eradication. Digestion 2008;78:113-119.

55. Seo JY, Lee DH, Cho Y, et al. Eradication of Helicobacter pylori reduces metachronous gastric cancer after endoscopic resection of early gastric cancer. Hepatogastroenterology 2013;60:776-780.

56. Chon I, Choi C, Shin CM, Park YS, Kim N, Lee DH. Effect of Helicobacter pylori eradication on subsequent dysplasia development after endoscopic resection of gastric dysplasia. Korean J Gastroenterol 2013;61:307-312.

57. Bae SE, Jung HY, Kang J, et al. Effect of Helicobacter pylori eradication on metachronous recurrence after endoscopic resection of gastric neoplasm. Am J Gastroenterol 2014;109:60-67.

58. Jung DH, Kim JH, Lee YC, et al. Helicobacter pylori eradication reduces the metachronous recurrence of gastric neoplasms by attenuating the precancerous process. J Gastric Cancer 2015;15:246-255.

59. Yoon SB, Park JM, Lim CH, Cho YK, Choi MG. Effect of Helicobacter pylori eradication on metachronous gastric cancer after endoscopic resection of gastric tumors: a meta-analysis. Helicobacter 2014;19:243-248.

60. Jung DH, Kim JH, Chung HS, et al. Helicobacter pylori eradication on the prevention of metachronous lesions after endoscopic resection of gastric neoplasm: a meta-analysis. PLoS One 2015;10:e0124725.

61. Mori G, Nakajima T, Asada K, et al. Incidence of and risk factors for metachronous gastric cancer after endoscopic resection and successful Helicobacter pylori eradication: results of a large-scale, multicenter co- hort study in Japan. Gastric Cancer 2016;19:911-918.

62. Ito M, Tanaka S, Takata S, et al. Morphological changes in human gastric tumours after eradication therapy of Helicobacter pylori in a shortterm follow-up. Aliment Pharmacol Ther 2005;21:559-566.

63. Kobayashi M, Hashimoto S, Nishikura K, et al. Magnifying narrow-band imaging of surface maturation in early differentiated-type gastric cancers after Helicobacter pylori eradication. J Gastroenterol 2013;48:1332-1342.

64. Yamamoto K, Kato M, Takahashi M, et al. Clinicopathological analysis of early-stage gastric cancers detected after successful eradication of Helicobacter pylori. Helicobacter 2011;16:210-216.

65. Moribata K, Iguchi JK, Nakachi K, et al. Endoscopic features associated with development of metachronous gastric cancer in patients who underwent endoscopic resection followed by Helicobacter pylori eradication. Dig Endosc 2015 Dec 1 [Epub]. https://doi.org/10.1111/den.12581.

66. National Comprehensive Cancer Network. NCCN clinical practice guidelines in oncology: gastric cancer version I. 2016 [Internet]. Fort Washington (PA): National Comprehensive Cancer Network; c2016 [cited 2016 Mar 31]. Available from: http://www.nccn.org/professionals/ physician_gls/PDF/gastric.pdf

67. Lieberman DA, Rex DK, Winawer SJ, Giardiello FM, Johnson DA, Levin TR. Guidelines for colonoscopy surveillance after screening and polypectomy: a consensus update by the US Multi-Society Task Force on Colorectal Cancer. Gastroenterology 2012;143:844-857.

68. Asada K, Nakajima T, Shimazu T, et al. Demonstration of the usefulness of epigenetic cancer risk prediction by a multicentre prospective cohort study. Gut 2015;64:388-396. 